\title{
Selective removal of chromium (VI) from sulphates and other metal anions using an ion-imprinted polymer
}

\author{
V Pakade ${ }^{1}$, E Cukrowska $^{1}$, J Darkwa $^{2}$, N Torto $^{3}$ and L Chimuka ${ }^{1 *}$ \\ ${ }^{1}$ School of Chemistry, University of the Witwatersrand, P/Bag 3, WITS 2050, Johannesburg, South Africa \\ ${ }^{2}$ Department of Chemistry, University of Johannesburg, PO Box 524, Auckland Park 2006, South Africa \\ ${ }^{3}$ Department of Chemistry, Rhodes University, PO Box 94, Grahamstown, 6140, South Africa
}

\begin{abstract}
A linear copolymer was prepared from 4-vinylpyridine and styrene. An ion-imprinted polymer (IIP) specific for $\mathrm{Cr}$ (VI) adsorption was prepared by copolymerisation of the quaternised linear copolymer (quaternised with 1,4-chlorobutane), 2-vinylpyridine functional monomer and ethylene glycol dimethacrylate (EGDMA), as the cross-linking monomer, in the presence of 1,1'-azobis(cyclohexanecarbonitrile) as initiator. Ammonium dichromate and aqueous methanol were used as a template and porogenic solvent, respectively. Leaching of the chromate template from the polymer particles was achieved with successive stirring of the ion-imprinted polymer (IIP) particles in $4 \mathrm{M} \mathrm{HNO}_{3}$ solutions to obtain leached materials, which were then used for selective rebinding of $\mathrm{Cr}(\mathrm{VI})$ ions from aqueous solutions. Similarly, the non-imprinted polymer/ control polymer (NIP/CP) material was also prepared under exactly the same conditions as the IIP but without the chromate anion template. Various parameters, such as solution $\mathrm{pH}$, initial concentration, aqueous phase volume, sorbent dosage, contact time and leaching solution volumes, were investigated. Scanning electron microscopy (SEM), Fourier Transform Infrared (FTIR) spectroscopy, BET surface area and pore size analysis were used for the characterisation of IIP (both unleached and leached) and CP materials. Optimal parameters were as follows: solution $\mathrm{pH}, 3$; contact time, $120 \mathrm{~min}$; eluent, $20 \mathrm{~m} \ell$ of $0.1 \mathrm{M} \mathrm{NaOH}$; and sorbent amount, $125 \mathrm{mg}$. Maximum retention capacity of IIP and CP was 37.58 and 25.44 $\mathrm{mg} \cdot \mathrm{g}^{-1}$, respectively. The extraction efficiencies of the IIP and CP were compared using a batch and SPE mode of extraction. In the absence of high concentrations of ions, especially sulphate ions, both CP and IIP demonstrated no differences in binding of $\mathrm{Cr}(\mathrm{VI})$, which was almost $100 \%$. However, in the presence of high concentrations of sulphate ions, the selectivity on the CP completely collapsed. The study clearly demonstrates the suitably of the developed IIP for selective extraction of $\mathrm{Cr}$ (VI) in complex samples such as those from acid mine drainage. The selectivity was also compared by direct injection of the real-world sample, both spiked and non-spiked, into that obtained after IIP selective extraction. Despite the method's very low detection limits for direct injection (below $\left.1 \mu \mathrm{g} \cdot \ell^{-1}\right), \mathrm{no} \mathrm{Cr}(\mathrm{VI})$ was obtained. However, after IIP selective extraction, spiked $\mathrm{Cr}(\mathrm{VI})$ was detected in the spiked sample.
\end{abstract}

Keywords: Ion-imprinted polymer, chromium (VI), acid mine drainage, selectivity

\section{Introduction}

Hexavalent chromium Cr (VI)), the most toxic and carcinogenic form of chromium, exists in most aquatic environments as water soluble oxyanions, $\mathrm{HCrO}_{4}{ }^{1-}$ or $\mathrm{CrO}_{4}{ }^{2-}$. Pulmonary congestion, liver damage, vomiting, and severe diarrhoea are some of the known health problems associated with $\mathrm{Cr}$ (VI) (Raji and Anirudhan, 1998). Chromium is mostly present in the +3 oxidation state in chromite, but can also exist in other oxidation states, ranging from -2 to +6 in different samples. Of these various oxidation states that chromium can exhibit, only the hexavalent and trivalent forms are known to have environmental importance (Goyal et al., 2003).

Chromium in the +6 oxidation state is regarded as a genotoxic, mutagenic and carcinogenic to humans and ecosystems (Chakraborty and Kumar, 2009) due to its solubility and a mobility which is 500 times (Sarin and Pant, 2006) and toxicity which is 100 times more than that of Cr (III) (Unnithan et al., 2001). Furthermore, $\mathrm{Cr}$ (VI) is declared as a Group 1 carcinogen by the US Environmental Protection Agency (US EPA,

\footnotetext{
* To whom all correspondence should be addressed.

욜 +27 11 717-6703; fax: +27 11 717-6749; e-mail: luke.chimuka@wits.ac.za

Received 13 January 2011; accepted in revised form 6 October 2011.
}

1999), while $\mathrm{Cr}$ (III) is known to be important for mammalian functions as it helps to maintain glucose, lipid and protein metabolism (Ramnani and Sabharwal, 2006). Due to its toxicity, hexavalent chromium has to be strictly regulated and as such the maximum permissible levels set out by the US EPA for both drinking water and wastewater are $0.05 \mathrm{mg} \cdot \ell^{-1}$ for $\mathrm{Cr}$ (VI) and $5 \mathrm{mg} \cdot \ell^{-1}$ for $\mathrm{Cr}$ (III), respectively (Acar and Malkoc, 2004). Anthropogenic sources, such as mining operations, leather tanning, metal plating, water cooling and pigment manufacturing, are responsible for water and soil contamination by chromium (Katz and Salem, 1994).

Various technologies, have been used for the removal of $\mathrm{Cr}$ (VI) including: reduction of $\mathrm{Cr}$ (VI) to $\mathrm{Cr}$ (III), followed by $\mathrm{Cr}$ (III) precipitation under alkaline conditions (Kratochvil et al., 1998); membrane separation, extraction, and sorption (Patterson, 1985); and sorption by activated carbon (Huang and $\mathrm{Wu}, 1977)$, ion exchangers (Santiago et al., 1992) and biosorbents (Brower et al., 1997). However, adsorption and ion exchange are the most common techniques used for the removal of $\mathrm{Cr}$ (VI) from aqueous environments (Neagu and Mikhalovsky, 2010). A range of natural and synthetic sorbents have been used (Srinivasan et al., 1988; Fang et al., 2007; Qian et al., 2000; Ramnani and Sabharwal, 2006; Deng and Bai, 2004; Raji and Anirudhan, 1998). Similarly, the use of ion exchangers for the removal of $\mathrm{Cr}$ (VI) has been reported in the literature, including the use of the commercial Aliquat 
336 (Vincent and Guibalf, 2001) and Lewatit-anion exchangers (Pehlivan and Cetin, 2009). Incomplete metal removal, expense, swelling (in case of resins), etc., are some of the drawbacks associated with some of the techniques. Ion-imprinted polymers (IIPs) offer several advantages, including high thermal stability and mechanical strength, over other polymeric materials.

The use of quaternised poly-(4-vinylpyridine) polymers for the removal of anionic species such as chromate, arsenate and perchlorate has been documented (Mitchell et al., 2004; Cannon et al., 2005). The quaternised polymeric molecules are known to possess both the hydrophobic groups and ionic moieties capable of undergoing ion exchange and ion pairing reactions, in aqueous environments, with the anionic species present (Fang et al., 2007). The reason for this is that, after quaternisation, the electron-deficient pyridine ring renders the pyridyl-N more attractive to anions than amine-N (Fang et al., 2007). Of particular interest to this study is the removal $\mathrm{Cr}$ (VI) from aqueous environmental samples using quaternised poly(4-vinylpyridine) incorporated in a molecular imprinted polymer backbone. This work is different from the studies reported by Fang et al. (2007) and Gang et al. (2000), who also used quaternised poly(4-vinylpyridine) for the removal of $\mathrm{Cr}$ (VI) from aqueous solutions - in the case reported by the former, the polymer was coated on activated carbon and in the case reported by the latter, the polymer was coated on silica gel particles. Ion-imprinted polymer backbones offer the sorbent stability in both alkaline and acidic conditions, as it is known that chromate can exist as $\mathrm{HCrO}_{4}^{-}$and $\mathrm{CrO}_{4}{ }^{2-}$ depending on concentration and $\mathrm{pH}$. Also, imprinting will improve the selectivity and pre-concentration effect, as compared to non-imprinted resins.

\section{Experiments}

\section{Instrumentation}

An ion chromatography system LC-CaDI 22-14 from Bischoff (Leonberg, Germany) equipped with a Lambda $1010 \mathrm{UV}-\mathrm{V}$ is absorbance detector was used for this work. The system consisted of an LC gradient mixer, 2 x HPLC compact pumps and a Variotherm. For system control and data collection a McDAcq32 Control chromatography workstation was used. An isocratic mode of elution was employed. A Dionex IonPac ${ }^{\circledR}$ AG $7(4 \times 50 \mathrm{~mm})$ guard column and Dionex IonPac ${ }^{\circ}$ AS7 (4 x $250 \mathrm{~mm}$ ) analytical column, all from Dionex (Sunnyvale, CA, USA) were used for all separations.

766 Calimatic $\mathrm{pH}$ meter from Knick (Berlin, Germany) was used for $\mathrm{pH}$ measurements. FTIR spectra were recorded in the frequency range of 4000 to $400 \mathrm{~cm}^{-1}$ using a Bruker FTIR spectrometer, Model Tensor 27 (Ettlingen, Germany) and spectra were recorded in the solid state.

\section{Materials and reagents}

A stock solution (1 $\left.000 \mathrm{mg} \cdot \ell^{-1}\right)$ of $\mathrm{Cr}(\mathrm{VI})$ was prepared by dissolving dried potassium dichromate, $\mathrm{K}_{2} \mathrm{Cr}_{2} \mathrm{O}_{7}$ (analytical reagent grade) in Milli-Q water. Working solutions were prepared daily from the stock solution through serial dilutions. The stock solution was stored at $4{ }^{\circ} \mathrm{C}$ when not in use. The $\mathrm{pH}$ was adjusted using dilute $\mathrm{HCl}$ or $\mathrm{NaOH}$ solutions. 1,4-Dichlorobutane from Fluka (Buchs, Switzerland), 1,5-diphenylcarbazide, 2-vinylpyridine (2-VP), 4-vinylpyridine (4-VP), ethylene glycol dimethacrylate (EGDMA), styrene and 1,1'-azobis(cyclohexanecarbonitrile) were used (all from Aldrich). Vinylpyridines were vacuum distilled prior to use. All other reagents were of AR grade, mostly from Merck. All HPLC solutions were filtered through a $0.45 \mu \mathrm{m}$ filter paper.

\section{Preparation of a linear copolymer of 4-vinylpyridine and styrene}

A linear polymer was prepared using a method reported by Li et al. (2005) with minor modifications. 4-vinylpyridine (3.154 g, $30 \mathrm{mmol})$, styrene ( $4.262 \mathrm{~g}, 30 \mathrm{mmol}$ ) and 1,1'-azobis(cyclohexane carbonitrile) $(50 \mathrm{mg})$ were dissolved in chloroform $(12 \mathrm{~m} \ell)$ to form a homogeneous solution. The mixture was purged with $\mathrm{N}_{2}$ for $10 \mathrm{~min}$; then thermal polymerisation was effected at $60^{\circ} \mathrm{C}$ for $12 \mathrm{~h}$. The resulting solution was diluted with chloroform and precipitated from petroleum ether (boiling point, $30-70^{\circ} \mathrm{C}$ ), filtered and dried under vacuum to give a light orange product $(3.384 \mathrm{~g})$.

\section{Preparation of ion-imprinted quaternised polymer}

A linear copolymer of 4-vinylpyridine and styrene (200 $\mathrm{mg}$ ), ammonium dichromate $(3 \mathrm{mmol})$ and 1,4 -dichlorobutane (DCB) $(18 \mathrm{mmol})$ were dissolved in methanol $(15 \mathrm{m \ell})$ for $30 \mathrm{~min}$. EGDMA (18 mmol), 2-VP ( $2 \mathrm{mmol})$ and $50 \mathrm{mg}$ 1,1 '- azobis(cyclohexane carbonitrile) were added while the solution was stirred under a stream of $\mathrm{N}_{2}$ in ice for $10 \mathrm{~min}$. Polymerisation was allowed to continue at $65^{\circ} \mathrm{C}$ for $48 \mathrm{~h}$. A black solid product was obtained, which was then washed with $\mathrm{MeOH}$ and water to remove unreacted reagents. Leaching of the chromate was afforded by the use of $4 \mathrm{M} \mathrm{HNO}_{3}$. The product was ground, crushed and wet-sieved in dichloromethane through 53-90 $\mu \mathrm{m}$. The CP was prepared in the same manner but omitting ammonium dichromate. The $\mathrm{CP}$ polymer was also treated with similar solutions to those used for treating the IIP and both were dried overnight at $55^{\circ} \mathrm{C}$. The prepared polymer was characterised by FTIR, among other techniques (Li et al., 2005). Schematic representation of IIP preparation is show in Scheme 1 .

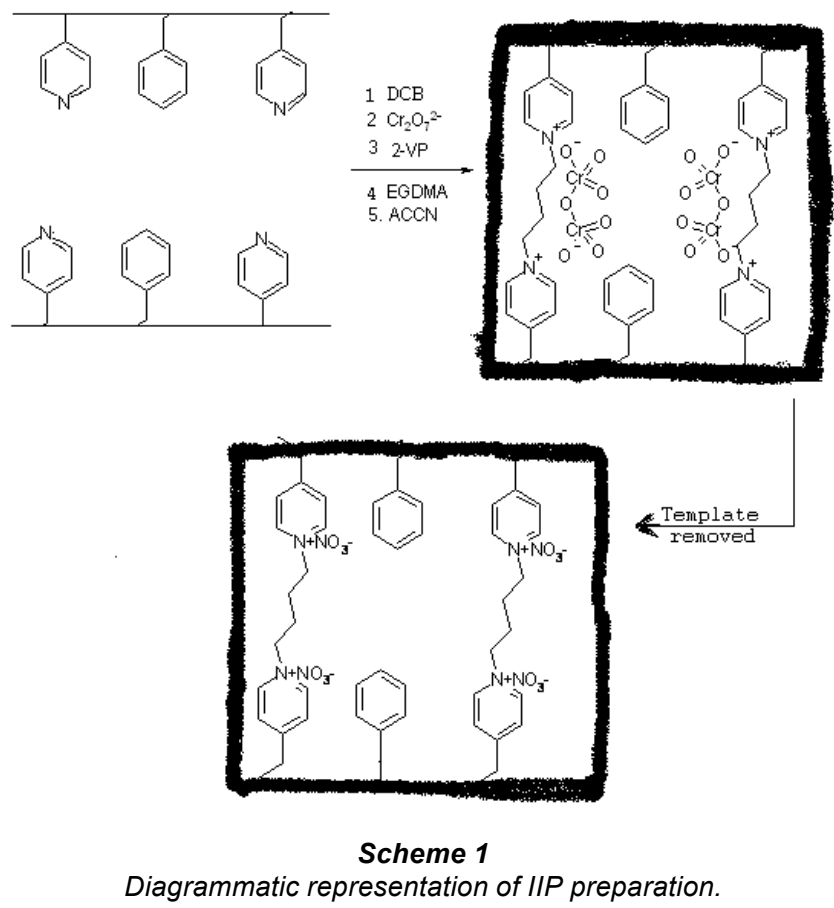

http://dx.doi.org/10.4314/wsa.v37i4.11 Available on website http://www.wrc.org.za 


\section{Adsorption studies}

Batch adsorption studies were performed by stirring $20 \mathrm{mg}$ of IIP or CP in a reaction vial containing $25 \mathrm{~m} \ell$ metal ion solution for $1 \mathrm{~h}$ at $\mathrm{pH} 2.6$ and at a temperature of $25.5^{\circ} \mathrm{C}$. The $\mathrm{pH}$ of the solutions was adjusted using dilute $\mathrm{HCl}$ and $\mathrm{NaOH}$ solutions. The concentration of unextracted $\mathrm{Cr}$ (VI) ions in solution was determined by IC-HPLC with post-column derivatisation. Adsorption equilibrium data obtained by varying $\mathrm{Cr}$ (VI) initial concentration $\left(0-300 \mathrm{mg} \cdot \ell^{-1}\right)$ were used to calculate maximum adsorption capacity for the IIP and $\mathrm{CP}$ at optimum conditions. Adsorption capacity of each metal was measured and calculated by the following equation (Birlik et al., 2007):

$$
Q=\frac{\left(C_{o}-C_{e}\right) V}{W}
$$

where:

$C_{o}$ and $C_{e}$ are the initial and final concentrations, respectively $V$ is the volume of the solution used for the extraction $W$ is the mass of the polymer used for extraction.

Per cent recovery $(R)$ was calculated using the following equation:

$$
\% R=\left[\frac{C_{o}-C_{e}}{C_{o}}\right] \times 100 \%
$$

\section{Optimisation studies}

The effect of amount of polymer (20-125 mg), solution phase volume $(25-700 \mathrm{~m} \ell)$, contact time (10-90 $\mathrm{min})$ and $\mathrm{pH}(1-4)$ of solution was studied. In all experiments $1.00 \mathrm{mg} \cdot \ell^{-1}$ of chromium (VI) present in aqueous phase was stirred with the appropriate amount of polymer, typically $20 \mathrm{mg}$ of IIP/ CP. The $\mathrm{pH}$ of the solution was controlled using $0.1 \mathrm{M} \mathrm{HCl}$ and $0.1 \mathrm{M} \mathrm{NaOH}$.

\section{Surface area measurements}

The surface area of leached IIP and CP was measured using BET instrument (Micromeritics Tristar). At least $0.3 \mathrm{~g}$ of sample was degassed in $\mathrm{N}_{2}$ at $150^{\circ} \mathrm{C}$ for $4 \mathrm{~h}$ prior to analysis, using a Micromeritics Flow Prep 060 sample degas system. The surface areas and pore size distributions were then obtained at $-196^{\circ} \mathrm{C}$. The pore size distribution for specific surface areas of the sample was determined via $\mathrm{N}_{2}$ adsorption/desorption according to the BET method, using a Micromeritics Tristar surface area and porosity analyser. In order to confirm the accuracy of the results, the analysis was repeated at least twice for all samples and the measurements were in good agreement. The specific surface area was calculated from the experimental values obtained from the desorption step.

\section{Selectivity studies}

In order to examine the selectivity of the prepared IIP, competitive adsorption of $\mathrm{Cl}^{-}, \mathrm{F}^{-}, \mathrm{NO}_{2}^{-}, \mathrm{NO}_{3}^{-}, \mathrm{SO}_{4}{ }^{2-}$ and $\mathrm{PO}_{4}{ }^{3-}$ with respect to $\mathrm{Cr}$ (VI) was studied. The studies were conducted in a multi-element mixture and in binary phases involving $\mathrm{Cr}$ (VI) and the respective anions. For each experiment, $20 \mathrm{mg}$ of IIP or $\mathrm{CP}$ in $25 \mathrm{~m} \ell$ of the abovementioned solutions was stirred for $1 \mathrm{~h}$ in reaction vials and the $\mathrm{pH}$ was adjusted to $\mathrm{pH} 2.63$ using $0.1 \mathrm{M} \mathrm{HCl}$. Initial solution concentration was $5 \mathrm{mg} \cdot \ell^{-1}$. The experiments were performed in a batch mode at optimum conditions and the remaining concentrations of each anion were measured.

Distribution coefficients $\left(K_{d}\right)$ of $\mathrm{Cl}^{-}, \mathrm{F}^{-}, \mathrm{NO}_{2}^{-}, \mathrm{NO}_{3}^{-}, \mathrm{SO}_{4}^{2-}$, $\mathrm{PO}_{4}{ }^{3-}$ and $\mathrm{Cr}(\mathrm{VI})$ were calculated as:

$$
K_{d}=\frac{\left(C_{o}-C_{e}\right) V}{C_{o} W}
$$

where:

$K_{d}$ is the distribution coefficient $\left(\mathrm{m} \ell \cdot \mathrm{g}^{-1}\right)$ and the other variables are as described for Eqs. (1) and (2).

According to Birlik et al. (2007) Eq. (3) can be used to calculate the selectivity coefficient for the binding of a metal ion in the presence of other competitive ions, from equilibrium binding data:

$$
K=\frac{K_{d}(\mathrm{Cr}(\mathrm{VI}))}{K_{d}(B)}
$$

where:

$K$ is the selectivity coefficient and

$B$ represents $\mathrm{Cl}^{-}, \mathrm{F}^{-}, \mathrm{NO}_{2}^{-}, \mathrm{NO}_{3}^{-}, \mathrm{SO}_{4}{ }^{2-}$ and $\mathrm{PO}_{4}{ }^{3-}$ anions.

The value of $K$ gives an indication as to how selective the polymer is for $\mathrm{Cr}$ (VI) ions in the presence of other anionic species in solution. Furthermore, the relative selectivity coefficient of IIP against $\mathrm{CP}$ was calculated from the following equation (Birlik et al., 2007):

$$
K^{\prime}=\frac{K_{\text {imprinted }}}{K_{\text {non-imprinted }}}
$$

where:

$K_{\text {imprinted }}$ and $K_{\text {non-imprinted }}$ are the selectivity coefficients of the IIP and CP, respectively. The value of $K^{\prime}$ represents the enhanced effect of imprinting on selectivity and adsorption affinity for the template compared to the non-imprinted polymer.

\section{Results and discussion}

\section{Characterisation}

\section{FTIR analysis}

The FTIR spectra of CP leached and unleached IIP (Fig. 1) all show a similar backbone indicative of the high levels of EGDMA cross-linking reagent used. The characteristic absorption bands in the range between 2958 and $2852 \mathrm{~cm}^{-1}$ in all polymers could be ascribed to methyl $(\mathrm{C}-\mathrm{H})$ stretching vibration absorption peaks, due to 1,4-dichlorobetane cross-linking agent. All 3 polymers show a strong vibration frequency at about $1720 \mathrm{~cm}^{-1}$, attributed to the carbonyl group of EGDMA polymers, and another distinctive vibration at $1150 \mathrm{~cm}^{-1}$ assigned to $\mathrm{C}-\mathrm{O}$ of EGDMA. In all spectra, a $\mathrm{C}=\mathrm{N}$ band in pyridine, usually at $1600 \mathrm{~cm}^{-1}$, is displaced to higher wave numbers $\left(1636 \mathrm{~cm}^{-1}\right)$ due to quaternisation ( $\mathrm{Li}$ et al., 2005). However, this band has low intensity in the unleached IIP indicating the onset of nitrogen-metal coordination bonds, which is in agreement with studies conducted by Ramos et al. (2000).

Other vibrations of interest are at $1454 \mathrm{~cm}^{-1}(\mathrm{CP}$ and leached IIP) and $1438 \mathrm{~cm}^{-1}$ (unleached IIP) assigned to C-C/ $\mathrm{N}-\mathrm{C}$. More important is the presence of a broad band at 3198 $\mathrm{cm}^{-1}$, and the bands between 900 and $778 \mathrm{~cm}^{-1}$ in the unleached IIP only; these could all be linked to the presence of $\mathrm{Cr}(\mathrm{VI})$ in the polymer as they are absent for both the leached and control polymer. This is in agreement with Goudarzian et al. (1996) 


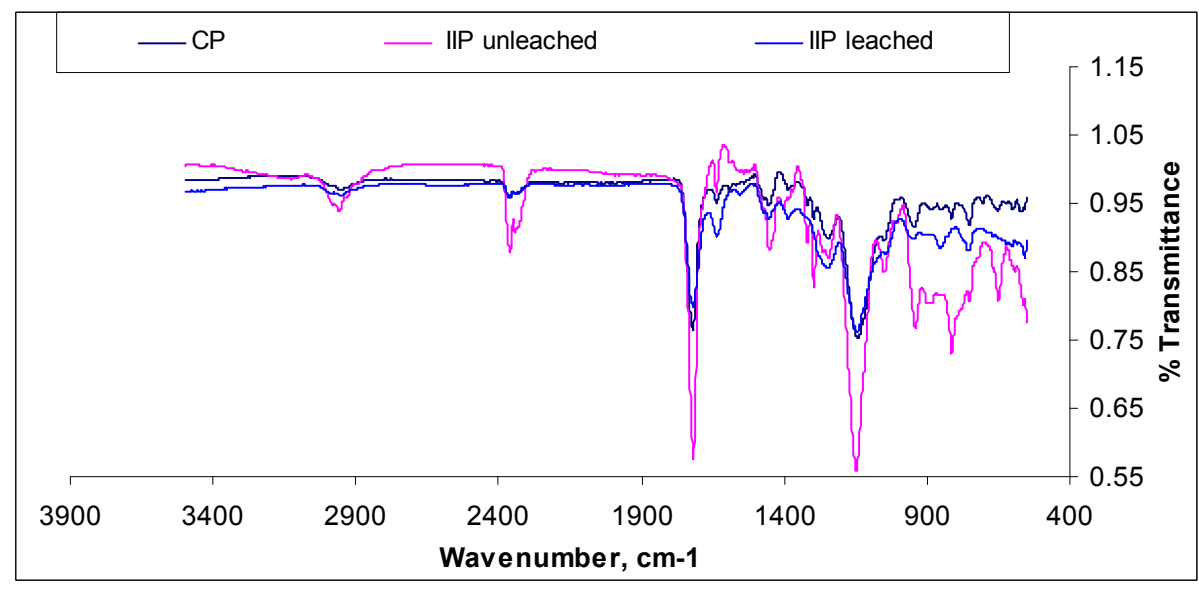

Figure 1

FTIR spectra of $C P$, leached IIP and unleached IIP

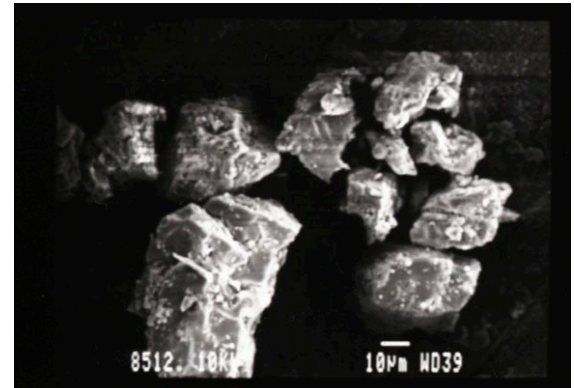

(a) IIP particles

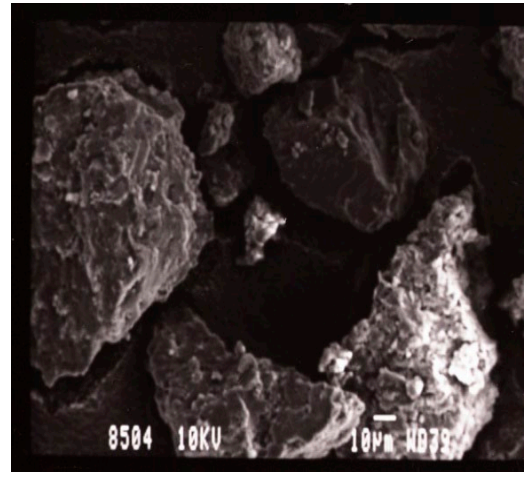

(a) CP particles

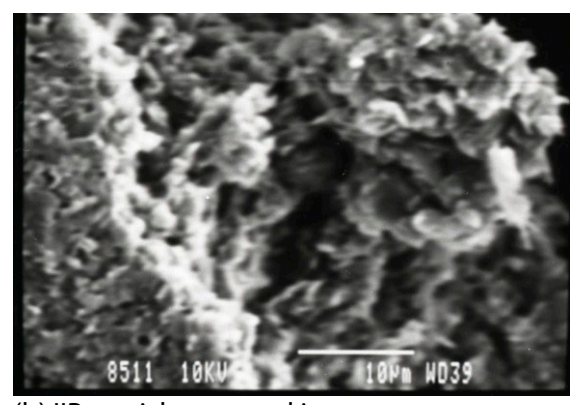

(b) IIP particle, zoomed in

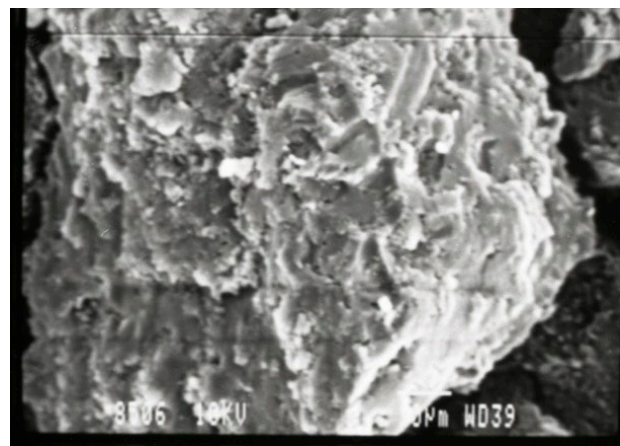

(b) CP particle, zoomed in
Figure 2

SEM images for IIP particles
Figure 3

SEM images for $C P$ particles who attributed bands at 938 and $790 \mathrm{~cm}^{-1}$ to the interaction of $\mathrm{Cr}$ (VI) with the adsorbent, and also with Miller and Wilkins (1952), who observed chromate anion FTIR bands at 930 and $765 \mathrm{~cm}^{-1}$ in polyethyleneimine-supported silver dichromate oxidising polymeric reagent. The FTIR spectrum of the quaternised polymer revealed the presence of 2 bands, at 1630 and $1578 \mathrm{~cm}^{-1}$, which indicate the presence of the quaternised product as these were absent in the vinylpyridine spectrum.

\section{Surface area measurements}

The surface area was determined using the BET method and values of 61.7 and $5.9 \mathrm{~m}^{2} \cdot \mathrm{g}^{-1}$ were obtained for IIP and CP, respectively. Although the ratios of IIP to CP surface areas are similar for both methods, there is a huge difference in the surface area values obtained. Three replicate experiments were conducted and for each experiment absorbance was measured in triplicate. The morphology of the particles was evaluated from SEM images. Images for IIP and CP are shown in Figs. 2(a) and 3(a); Figs. 2(b) and 3(b) show zoomed-in images for a single particle. From the images it can be concluded that the particles produced for both CP and IIP have irregular shapes with some degree of porous surface that will aid in adsorption. In fact, Figs. 2(b) and 3(b) reveal that the polymers have similar surface structures, which further confirms the similarities in binding results obtained for both polymers.

\section{Optimisation studies}

For the optimisation studies discussed below for the IIP and CP only the batch method was employed.

\section{Optimisation of leaching}

Leaching and washing of the retained $\mathrm{Cr}$ (VI) from the polymers was performed using $0.1 \mathrm{M} \mathrm{NaOH}$ (Fig. 4). The results indicate that $10 \mathrm{~m} \ell$ of $0.1 \mathrm{M} \mathrm{NaOH}$ was not enough to leach out any $\mathrm{Cr}$ (VI) on the polymer. $20 \mathrm{~m} \ell$ was therefore taken as optimum. This is important to avoid IIP bleeding as well as to achieve complete recovery of bound $\mathrm{Cr}(\mathrm{VI})$. A relatively large 


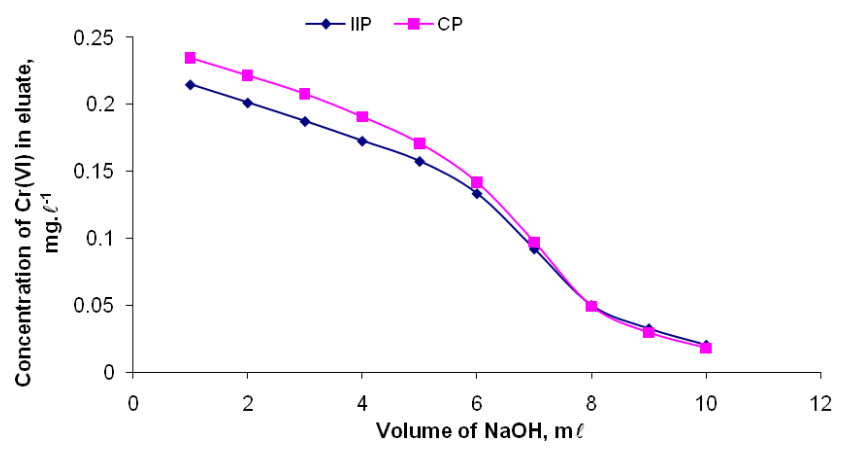

Figure 4

Leaching and washing of the retained chromate after rebinding. Amount of material, $20 \mathrm{mg}$; solution $\mathrm{pH}$, 3; leaching solution, $1 \mathrm{ml}$ of $0.1 \mathrm{M} \mathrm{NaOH}$; material eluted from SPE cartridges.

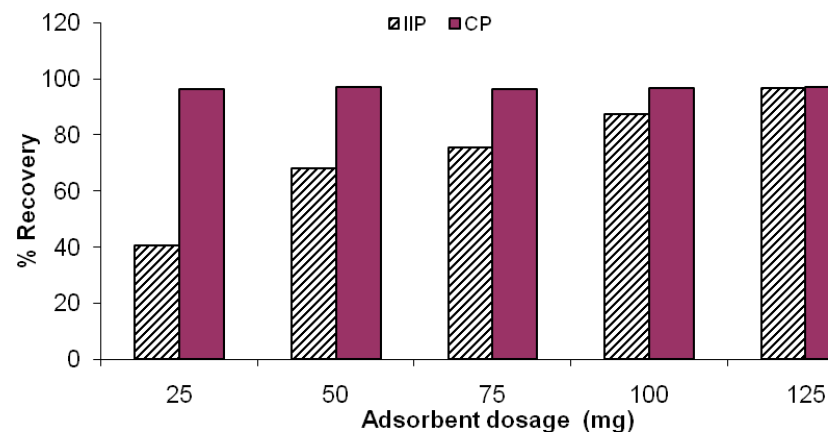

Figure 5

Effect of sorbent dosage of IIP and CP. Solution $\mathrm{pH}, 3.0$; concentration of solution, $1 \mathrm{mg} \cdot \ell^{1}$; volume of solution, $25 \mathrm{m \ell}$; contact time, $120 \mathrm{~min}$

elution volume meant low analyte concentration enrichment but this did not pose any limitations because the HPLC-UV method is very sensitive, with a detection limit below $1 \mu \mathrm{g} \cdot \ell^{-1}$ with direct injection of pure standard.

\section{Optimisation of IIP quantity needed for maximum extraction of $\mathrm{Cr}$ (VI)}

Different amounts of Cr (VI) imprinted polymer $(25,50,75,100$ and $125 \mathrm{mg}$ ) were stirred for $1 \mathrm{~h}$ in various sample vials containing $25 \mathrm{~m} \ell$ aliquots of $1 \mu \mathrm{g} \cdot \mathrm{m}^{-1} \mathrm{Cr}$ (VI) spiked water and the $\mathrm{pH}$ was adjusted to 3.0. This $\mathrm{pH}$ was chosen based on the 2 earlier batch studies, where maximum adsorption occurred around $\mathrm{pH}$ 3. All of the experiments were conducted in triplicate and the mean values and standard deviations were determined.

From Fig. 5, CP showed a maximum constant adsorption of $\mathrm{Cr}$ (VI) of about $98 \%$, where $25-125 \mathrm{mg}$ of the polymer was used. Hence, $30 \mathrm{mg}$ can be regarded as optimum for this type of polymer. However, the adsorption increases steadily for the IIP and seem to reach maximum at $125 \mathrm{mg}$. Therefore, $130 \mathrm{mg}$ was taken as an optimum for this polymer.

\section{Effect of $\mathrm{pH}$}

The effect of $\mathrm{pH}$ on the extraction of chromium (VI) ions by IIP and CP was investigated by varying the $\mathrm{pH}$ from 1 to 4 ; results are shown in Fig. 6. From Fig. 6, it can be noted that there was no major variation in the influence of sample $\mathrm{pH}$, within the range studied. Similar results where adsorption was independent of $\mathrm{pH}$ were reported by Neagu (2009) and Neagu and Mikhalovsky (2010) for their use of quaternised

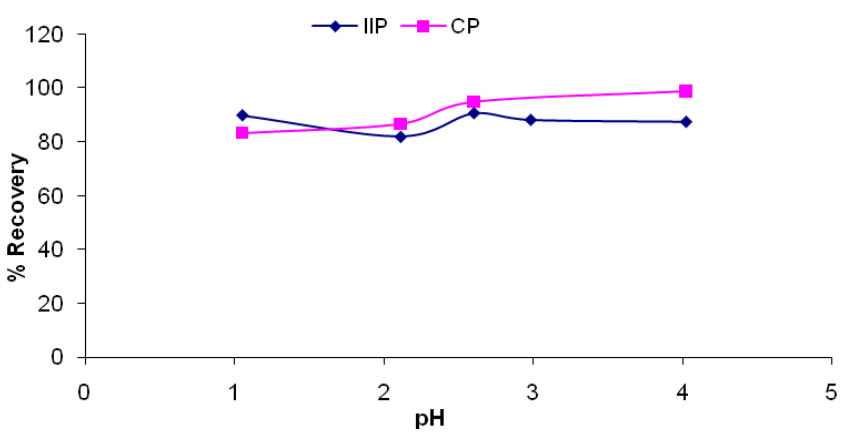

Figure 6

Effect of $\mathrm{pH}$ on the extraction of chromium (VI) ions by CP and IIP. Amount of materials, $20 \mathrm{mg}$; concentration of solution,

$1 \mathrm{mg} \cdot \ell^{-1}$; volume of solution, $25 \mathrm{m \ell}$; contact time, $120 \mathrm{~min}$.

crosslinked pyridine polymers.

Tunçeli and Türker (2002) obtained a similar relationship between $\mathrm{pH}$ and adsorption behaviour, where $\mathrm{Cr}$ (VI) adsorption was constant at about $75 \%$ recovery from $\mathrm{pH} 2$ to $\mathrm{pH} 8$. It is known that $\mathrm{Cr}(\mathrm{VI})$ exists in different stable forms in aqueous solutions and that the predominance of various species is $\mathrm{pH}$ dependent. For example, $\mathrm{Cr}_{2} \mathrm{O}_{7}{ }^{2-}$ and $\mathrm{HCrO}_{4}{ }^{1-}$ are more common in the $\mathrm{pH}$ range 2.0-6.0, whereas $\mathrm{CrO}_{4}^{2-}$ predominates in basic solutions (Benhammou et al., 2007). The ionic strength of a solution increases with the decrease in $\mathrm{pH}$ and under such conditions one would expect that removal of $\mathrm{Cr}$ (VI) would be lower at low $\mathrm{pH}$ ranges (1.0-3.0) due to competition for binding sites between $\mathrm{Cr}(\mathrm{VI})$ and the $\mathrm{Cl}^{-}$anions used for $\mathrm{pH}$ adjustments. Furthermore, above $\mathrm{pH} 7$, competition for the active binding sites from $\mathrm{OH}^{-}$ions used for $\mathrm{pH}$ adjustments is expected to decrease the removal of $\mathrm{Cr}$ (VI). However, both these theoretical predictions were not observed, in this study or in a study by Tunçeli and Türker (2002). Both of the theoretical predictions are influenced by the selectivity of the polymer towards $\mathrm{Cr}(\mathrm{VI})$, the capacity of the polymer and the amount of interfering ions.

\section{Effect of contact time}

The effect of contact time on the extraction of chromium (VI) ions by IIP and CP was studied by stirring $20 \mathrm{mg}$ of polymer with $1 \mathrm{mg} \cdot \ell^{-1}$ solution of chromium at $\mathrm{pH} 3.0$ for $10,30,60$ and $90 \mathrm{~min}$ (Fig. 7). Although both polymers showed greater than $85 \%$ recovery for all of the contact times investigated, the IIP was shown to have a faster binding kinetic, as $92 \%$ recovery was obtained, compared to $88 \%$ after the first 10 minutes of stirring. However, after 20 min of stirring it was the CP that showed higher recovery and seemed to have reached a plateau after $60 \mathrm{~min}$. The recovery for the IIP after $90 \mathrm{~min}$ was $97 \%$ and was still on the rise; hence, 120 min was taken as an optimum stirring time for IIP and CP.

\section{Effect of solution volume}

Twenty mg of IIP and CP were stirred in solutions containing $1 \mathrm{mg} \cdot \ell^{-1}$ chromium, of different volumes $(50-700 \mathrm{~m} \ell)$. The results for both polymers show a similar trend, further emphasising that these (polymers) are actually the same (Fig. 8). The shape of the graph in Fig. 8 can be explained in terms of the mass transfer of chromium from the bulk solution to the IIP and CP particles. The smaller the volume, the shorter the contact time needed for chromium in solution to come into contact with IIP particles, as the distance between the IIP or CP particles 


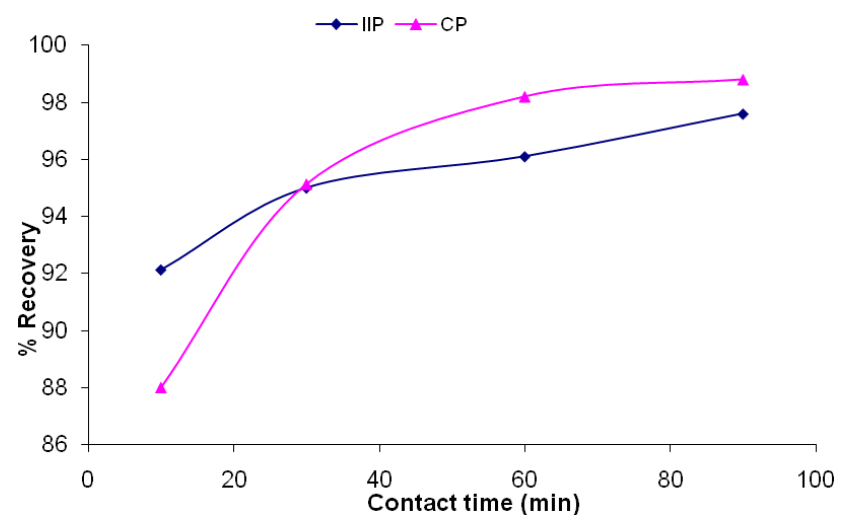

Figure 7

Effect of contact time on extraction of chromium (VI) ion by IIP and CP. Amount of materials, $20 \mathrm{mg}$; solution $\mathrm{pH}, 3$; concentration of solution, $1 \mathrm{mg} \cdot \ell^{-1}$; volume of solution, $25 \mathrm{m \ell}$.

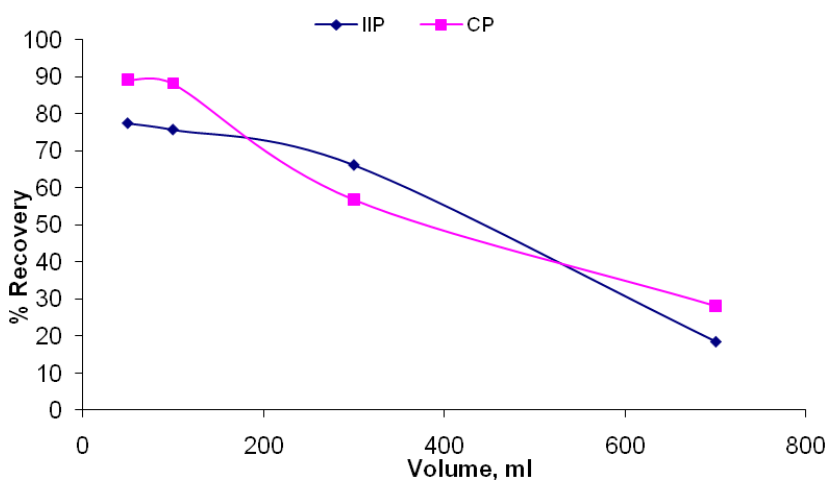

Figure 8

Effect of solution volume on extraction of chromium (VI) ion by IIP and CP. Amount of materials, $20 \mathrm{mg}$; solution $\mathrm{pH}, 3$; concentration of solution, $1 \mathrm{mg} \cdot \ell^{-1}$; contact time, $120 \mathrm{~min}$.

and chromium in solution will be smaller than it will be in larger volumes.. This explains the low recoveries obtained for larger volumes of solution. The recovery is generally constant and independent of sample volume when the polymer is packed in a cartridge, as in SPE, until the breakthrough volume is exceeded; this is somewhat different from what is observed in Fig. 8.

\section{Retention capacity}

The maximum adsorption capacity for the polymer was investigated and the results are shown in Fig. 9. For the range of concentrations studied, the IIP reached a plateau around 38 $\mathrm{mg} \cdot \mathrm{g}^{-1}$, while the CP seems to reach a plateau at $25 \mathrm{mg} \cdot \mathrm{g}^{-1}$. This result illustrates that, although the IIP and CP seem to have similar adsorption capabilities towards the chromate anion, as

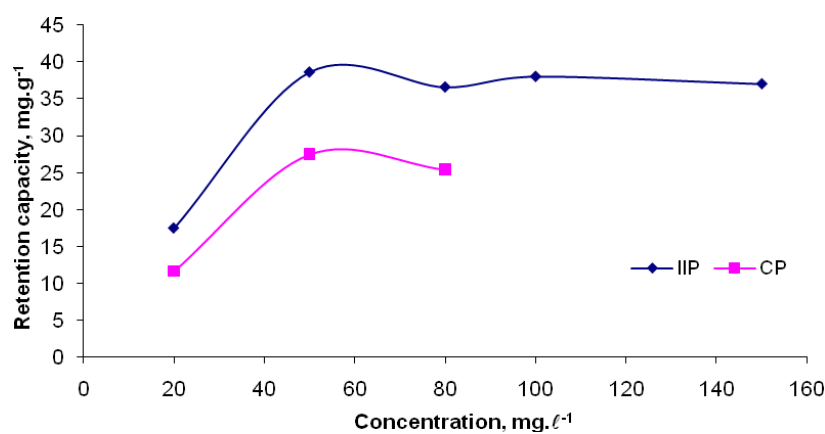

Figure 9

Retention capacity verses concentration of $\mathrm{Cr}(\mathrm{VI})$ in solution. Amount of IIP particles, $20 \mathrm{mg}$; solution $\mathrm{pH}$, 3; solution volume, $25 \mathrm{ml}$; contact time, $120 \mathrm{~min}$.

indicated by the other experiments, the IIP actually has more binding sites due to imprinting. This means that the IIP can be deployed for environmental remediation for longer periods than the $\mathrm{CP}$ as it has higher binding capacity.

\section{Binding studies}

Binding studies using batch and solid-phase extraction methods (SPE) were compared and the results are presented in Table 1. Experimental parameters are given in the Table and the values reported are mean values. Percent recoveries obtained by both batch and SPE method show that the IIP can be used succefully for extraction of chromium (VI) with either method of extraction. $\% \mathrm{RSD}$ values are given in brackets.

\section{Adsorption isotherms}

The Langmuir and Freundlich models were used to study the adsorption of $\mathrm{Cr}$ (VI) on the IIP particles. The Langmuir model was first developed to describe the vapour adsorption on homogeneous surfaces. However, when used for solid-liquid systems several assumptions are made. These assumptions are: number of surface adsorption sites is fixed; adsorption involves a single monolayer; adsorption behaviour is independent of surface coverage; and all adsorption sites are represented by similar types of functional groups. The Langmuir equation is given by:

$$
C_{e} / q_{e}=C_{e} / Q_{o}+1 / b Q_{o}
$$

where:

$q_{e}$ is the amount of solute adsorbed on the surface of adsorbent $\left(\mathrm{mg} \cdot \mathrm{g}^{-1}\right)$

$C_{e}$ is the equilibrium $\mathrm{Cr}(\mathrm{VI})$ concentration $\left(\mathrm{mg} \cdot \mathrm{m} \ell^{-1}\right)$

$Q_{o}$ is the saturated monolayer adsorption capacity $\left(\mathrm{mg} \cdot \mathrm{g}^{-1}\right)$

$b$ is the Langmuir adsorption constant $\left(\ell \cdot \mathrm{mg}^{-1}\right)$

\begin{tabular}{|l|c|c|c|c|}
\hline \multicolumn{5}{|c|}{ Table 1 } \\
\hline & Batch & & \multicolumn{2}{c|}{ SPE } \\
\hline & IIP & CP & IIP & CP \\
\hline Polymer $(\mathrm{mg})$ & 30 & 20 & 20 & 20 \\
\hline $\mathrm{pH}$ & 3 & 3 & 3 & 3 \\
\hline Sample $(\mathrm{m} \ell)$ & 30 & 25 & 25 & 25 \\
\hline Concentration added $\left(\mu \mathrm{g} \cdot \ell^{-1}\right)$ & 1000 & 1000 & 1000 & 1000 \\
\hline Extraction time $(\mathrm{min})$ & 95 & 30 & - & - \\
\hline$\%$ Recovery & $98 \pm 0.19$ & $91 \pm 2.48$ & $96 \pm 0.37$ & $98 \pm 0.52$ \\
\hline
\end{tabular}




\begin{tabular}{|c|c|c|c|c|c|c|c|}
\hline \multicolumn{8}{|c|}{$\begin{array}{l}\text { Table } 2 \\
\text { Langmuir and Freundlich adsorption isotherm constant values determined for the IIP and CP }\end{array}$} \\
\hline \multirow[t]{2}{*}{ Polymers } & \multirow{2}{*}{\begin{tabular}{c|} 
Experimental \\
$q_{\text {exp }}\left(m g \cdot g^{-1}\right)$ \\
\end{tabular}} & \multicolumn{3}{|c|}{ Langmuir Model } & \multicolumn{3}{|c|}{ Freundlich Model } \\
\hline & & $q_{\max }\left(\mathbf{m g} \cdot \mathbf{g}^{-1}\right)$ & $b$ & $R^{2}$ & $K_{F}$ & $N$ & $R^{2}$ \\
\hline IIP & 38.43 & 45.23 & $7.8 \times 10^{-3}$ & 0.97 & 5.08 & 1.46 & 1.00 \\
\hline $\mathrm{CP}$ & 25.44 & 34.31 & $3.6 \times 10^{-2}$ & 0.96 & 5.55 & 2.61 & 0.65 \\
\hline
\end{tabular}

A plot of $C_{e} / q_{e}$ versus $C e$ gives the values of $Q_{o}$ and $b$ (Wang et al., 2009). The Freundlich adsorption isotherm which assumes a multilayer adsorption can be given by the linearised form:

$$
\ln q_{e}=\ln K_{F}+1 / n \ln C_{e}
$$

where:

$K_{F}$ is the Freundlich constant

$n$ is the Freundlich exponent

The experimental values for $q_{\text {exp }}$ and $q_{\max }$ are comparable. The initial solution concentrations used were in the range of 10-100 $\mathrm{mg} \cdot \ell^{-1}$. In the Freundlich approach the values of $n$ are both greater than 1 indicating favourable adsorption of $\mathrm{Cr}(\mathrm{VI})$ on the adsorbent (Candan et al., 2009).

Table 2 summarises the results obtained by fitting the experimental data to the 2 models, namely, the Langmuir and Freundlich adsorption isotherms. Results for the IIP fit both models, whereas results for the CP did not show a good fit for the Freundlich model. This can be explained by the fact that the Freundlich model follows a multilayer mode of adsorption. The $\mathrm{CP}$ can be predicted to favour a single layer mode of adsorption (surface adsorption), whereas in the IIP there are surface as well as some deep embedded cavities for adsorption, making IIP a multilayer adsorbent.

\section{Effect of ionic strength}

The study of the influence of ionic strength is important for the adsorption of $\mathrm{Cr}(\mathrm{VI})$ as wastewater contains different ions (Anirudhan et al., 2009). The results are depicted in Fig. 10. Consistent with the literature (Li and Bowman, 2001; Fang et al., 2007), the sorption of $\mathrm{Cr}$ (VI) decreased with increasing ionic strength, meaning that $\mathrm{Cr}$ (VI) sorption is affected by exchange reactions (Fang et al., 2007). In fact, ion activity of chromium ions decreases with increase in ionic strength $(\mathrm{Li}$ and Bowman, 2001). The ion exchange process taking place on the surface of the polymer can be represented as:

$$
\mathrm{X}-\mathrm{Cl}+\mathrm{HCrO}_{4}^{-}=\mathrm{X}-\mathrm{HCrO}_{4}+\mathrm{Cl}^{-} \quad K_{V}\left(\mathrm{Cl}-\mathrm{HCrO}_{4}\right)
$$

where:

$K_{V}\left(\mathrm{Cl}-\mathrm{HCrO}_{4}\right)$ is the Vanselow selectivity coefficient (Fang et al., 2007).

According to Lee et al. (2005), if the change in ionic strength does not lead to any appreciable change in the removal of the chromate then the mechanism for removal might be due to precipitation and covalent bonding. Ions that form outer-sphere complexes show decreasing adsorption as the ionic strength is increased (McBride, 1997). The decrease in Cr (VI) adsorption with increase in ionic strength can be said to obey this theory. This decrease is due to the competition for specific binding sites between the chromate and the chloride anions present in solution. The IIP showed slightly higher recovery than the

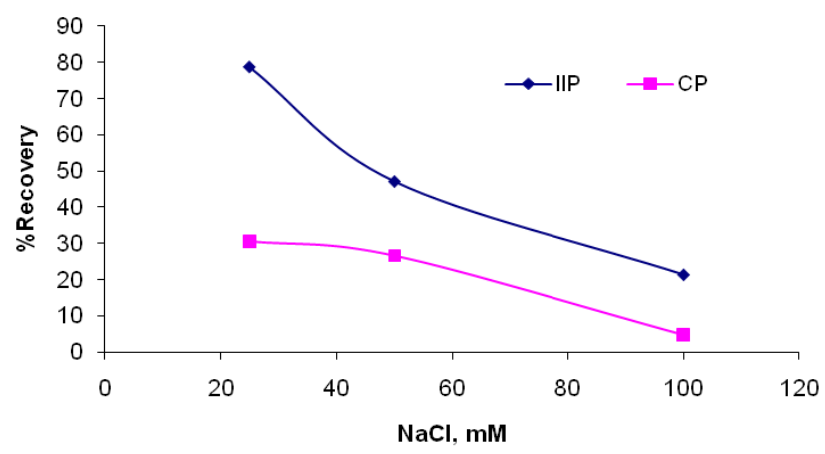

Figure 10

Effect of ionic strength. $20 \mathrm{mg}$ of polymer was stirred in a 1 $\mathrm{mg} \cdot \ell^{-1}$ chromium solution containing different concentrations of $\mathrm{NaCl}$ (25-300 mM, 900-3 $\left.500 \mathrm{mg} \cdot \ell^{-1}\right)$; solution $\mathrm{pH}$. 3; solution volume, $25 \mathrm{m \ell}$; contact time, $120 \mathrm{~min}$.

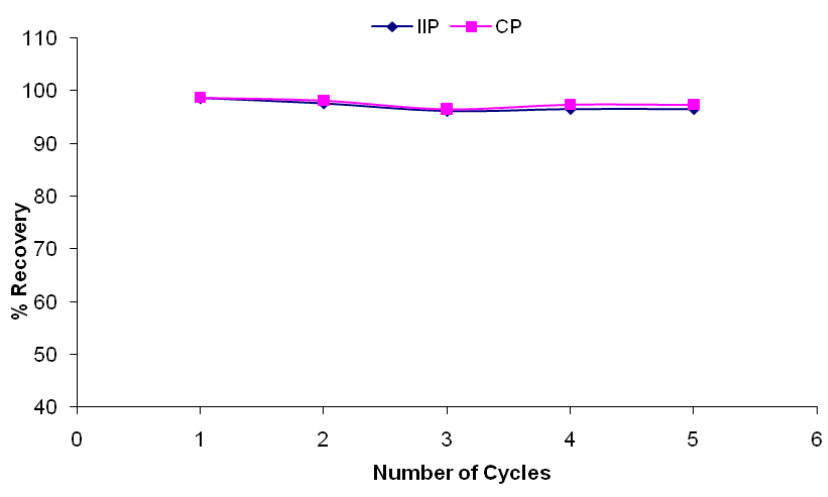

Figure 11

Reusability and stability of the polymers. Amount of polymer, $20 \mathrm{mg}$; solution $\mathrm{pH}$, 3; solution volume, $25 \mathrm{ml}$; contact time, 120 min, concentration of solution, $1 \mathrm{mg} \cdot \ell^{-1}$.

$\mathrm{CP}$, which is also evidence of the imprinting effect. IIPs are therefore generally superior in selectivity compared to normal polymers with chelating functional groups.

\section{Stability and reusability}

The effect of reusability and stability of the polymers was studied by stirring $20 \mathrm{mg}$ of polymer in $1 \mathrm{mg} \cdot \ell^{-1}$ solution of chromium for $60 \mathrm{~min}$. Optimum conditions were used for other variables. After leaching with $0.1 \mathrm{M} \mathrm{NaOH}$ the polymers were used for the next rebinding without conditioning. The results are illustrated in Fig. 11. The polymers yielded greater than $96 \%$ extraction efficiency for up to 5 cycles.

\section{Effect of co-existing anions}

Competitive adsorption of $\mathrm{Cr}(\mathrm{VI}) / \mathrm{Cl}^{-}, \mathrm{Cr}(\mathrm{VI}) / \mathrm{F}^{-}, \mathrm{Cr}$ (VI) / $\mathrm{NO}_{2}^{-}, \mathrm{Cr}(\mathrm{VI}) / \mathrm{NO}_{3}^{-}, \mathrm{Cr}(\mathrm{VI}) / \mathrm{SO}_{4}{ }^{2-}, \mathrm{Cr}(\mathrm{VI}) / \mathrm{PO}_{4}{ }^{3-}$ and 


\begin{tabular}{|c|c|c|c|c|c|c|c|c|c|}
\hline \multicolumn{10}{|c|}{$\begin{array}{c}\text { Table } 3 \\
\text { Distribution coefficient and selectivity factor for IIP and CP }\end{array}$} \\
\hline \multirow{2}{*}{ Adsorbent } & \multicolumn{2}{|c|}{$K d$} & \multirow[t]{2}{*}{$K$} & \multirow[t]{2}{*}{$K^{\prime}$} & \multirow{2}{*}{ Adsorbent } & \multicolumn{2}{|c|}{$K d$} & \multirow[t]{2}{*}{$K$} & \multirow[t]{2}{*}{$K^{\prime}$} \\
\hline & $\mathrm{Cr}(\mathrm{VI})$ & $\mathrm{Cl}^{-}$ & & & & $\mathrm{Cr}(\mathrm{VI})$ & $\mathrm{SO}_{4}^{2-}$ & & \\
\hline $\mathrm{CP}$ & 423.6 & N.D & & & $\mathrm{CP}$ & 274.5 & 109 & 2.5 & \\
\hline IIP & 442.7 & N.D & & & IIP & 347 & 249.9 & 1.4 & 0.55 \\
\hline \multirow{2}{*}{ Adsorbent } & \multicolumn{2}{|c|}{$K d$} & $K$ & $K^{\prime}$ & \multirow{2}{*}{ Adsorbent } & \multicolumn{2}{|c|}{$K d$} & $K$ & $K^{\prime}$ \\
\hline & $\mathrm{Cr}(\mathrm{VI})$ & $\mathrm{F}^{-}$ & & & & $\mathrm{Cr}(\mathrm{VI})$ & $\mathrm{PO}_{4}^{3-}$ & & \\
\hline $\mathrm{CP}$ & 328.6 & 37.8 & 8.7 & & $\mathrm{CP}$ & 379.2 & 127.5 & 3.0 & \\
\hline IIP & 350.3 & 0.1 & 3503.0 & 403.0 & IIP & 383.6 & 138.4 & 2.8 & 0.93 \\
\hline \multirow{2}{*}{ Adsorbent } & \multicolumn{2}{|c|}{$K d$} & $K$ & $K^{\prime}$ & \multirow{2}{*}{ Adsorbent } & \multicolumn{2}{|c|}{$K d$} & $K$ & $K^{\prime}$ \\
\hline & $\mathrm{Cr}(\mathrm{VI})$ & $\mathrm{NO}_{3}^{-}$ & & & & $\mathrm{Cr}(\mathrm{VI})$ & $\mathrm{NO}_{2}^{-}$ & & \\
\hline $\mathrm{CP}$ & 408 & 105.2 & 3.9 & & $\mathrm{CP}$ & 434.2 & 69.3 & 6.3 & \\
\hline IIP & 412.5 & 376.4 & 1.1 & 0.28 & IIP & 395.4 & 488 & 0.81 & 0.13 \\
\hline
\end{tabular}

\begin{tabular}{|c|c|c|c|c|c|c|c|}
\hline $\begin{array}{r}\text { Analy } \\
\text { of reference mat }\end{array}$ & $\begin{array}{l}\text { of tap-w } \\
\text { I. Amou }\end{array}$ & $\begin{array}{l}\text { Bokkan } \\
\text { f polyme }\end{array}$ & $\begin{array}{l}\mathrm{m} 2 \text { an } \\
\mathrm{d}, 20 \mathrm{~m} \\
\text { conce }\end{array}$ & $\begin{array}{l}\text { e } 4 \\
\text { id mine } \mathrm{dr} \\
\text { olution } \mathrm{pH} \\
\text { tion, } 30 \mu \mathrm{g}\end{array}$ & $\begin{array}{l}\text { ge water spik } \\
\text { solution volu }\end{array}$ & $\begin{array}{l}\text { vith } 30 \\
25 \mathrm{me} ;\end{array}$ & time, 10 \\
\hline & & rect anals & & Concentra & fr (VI) by IIP & $\% \operatorname{Re}$ & $\operatorname{Cr}(\mathrm{VI})$ \\
\hline Samples & $\mu \mathrm{g} \cdot \ell^{-1}$ & $\mathrm{mg} \cdot \ell^{-1}$ & $\mathrm{mg} \cdot \ell^{-1}$ & & & & \\
\hline & $\mathrm{Cr}(\mathrm{VI})$ & $\mathrm{Cl}^{-}$ & $\mathrm{SO}_{4}{ }^{2-}$ & Added & Measured ${ }^{a}$ & CP & IIP \\
\hline & - & 0.87 & 1.03 & 0.00 & - & - & - \\
\hline Tap-water & - & 0.87 & 1.03 & 30.00 & $29.19 \pm 7.44$ & 93.11 & 97.26 \\
\hline & 2.26 & 4.61 & 19.41 & 30.00 & $33.74 \pm 4.53^{b}$ & - & - \\
\hline Bokkamp Dam 2 & 2.26 & 4.61 & 19.41 & 30.00 & $15.70 \pm 6.69$ & 4.56 & 47.68 \\
\hline & no peak & & & 0.00 & - & - & - \\
\hline AMD wastewater & no peak & & & 30.00 & $25.87 \pm 6.15$ & 18.13 & 70.08 \\
\hline${ }^{\mathrm{a}}$ Mean of triplicate & RSD & Spiked s & before & action & & & \\
\hline
\end{tabular}

$\mathrm{Cr}(\mathrm{VI}) /\left\{\mathrm{Cl}^{-}, \mathrm{F}^{-}, \mathrm{NO}_{2}^{-}, \mathrm{NO}_{3}^{-}, \mathrm{SO}_{4}^{2-}\right.$ and $\left.\mathrm{PO}_{4}^{3-}\right\}$ was investigated; the results are summarised in Table 3 . In terms of recognition of the chromate anion the data are in agreement with those obtained previously (Table 1), in that the IIP and CP seem to adsorb chromate to the same extent (Table 3). The distribution coefficients, $K_{D}$, and the selectivity coefficients, $K$, for the IIP and $\mathrm{CP}$ are comparable, further emphasising that the polymers are similar. However, chloride anions could not be quantified by IC because: $\mathrm{Cl}^{-}$was used to adjust $\mathrm{pH}$ (in the form of $\mathrm{HCl}$ ); and $\mathrm{Cl}^{-}$was used during quaternisation (as 1,4-dichlorobutane). Therefore, it was understandable that there would be a high concentration of the chloride ions in the samples.

The influence of the investigated co-existing anions on $\mathrm{Cr}$ (VI) sorption can be summarised as following the order: $\mathrm{SO}_{4}{ }^{2-}>\mathrm{F}^{-}>\mathrm{PO}_{4}{ }^{3-}>\mathrm{NO}_{2}{ }^{-}>\mathrm{NO}_{3}{ }^{-}>\mathrm{Cl}^{-}$. The evaluated order is slightly different to that reported by Fang et al. (2007), who investigated the influence of $\mathrm{SO}_{4}{ }^{2-}, \mathrm{PO}_{4}^{3-}$ and $\mathrm{NO}_{3}{ }^{-}$on $\mathrm{Cr}$ (VI) sorption using $0.1,1.0$ and $10 \mathrm{mM}$ concentrations of anions. The observed trend was $\mathrm{PO}_{4}^{3-}>\mathrm{SO}_{4}{ }^{2-}>\mathrm{NO}_{3}{ }^{-}$whereas our studies indicated that sulphates compete more for binding sites than phosphates.

\section{Application to real samples}

A screening experiment was performed using a batch mode of extraction. The experiment was done to explore the application of the prepared polymers to real-world samples. Samples from Bokkamp Dam 2, acid mine drainage water and tap-water were adjusted to $\mathrm{pH} 3.0$ and spiked with $30 \mu \mathrm{g} \cdot \ell^{-1} \mathrm{Cr}(\mathrm{VI})$ of a certified reference material (CRM QCl-034-3). The CRM value was below $50 \mu \mathrm{g} \cdot \ell^{-1}$ which is the maximum allowable limit of $\mathrm{Cr}$ (VI) in drinking water. After batch experiments were conducted, unextracted and extracted concentrations of $\mathrm{Cr}$ (VI) were determined; results are shown in Table 4. Unspiked tap-water and Bokkamp Dam 2 water were run as a blank, and $\mathrm{Cr}$ (VI) quantified was zero and $2.24 \mu \mathrm{g} \cdot \ell^{-1}$, respectively (Table 4). For tap-water both the CP and IIP showed high recoveries, of about $95 \%$, which is in agreement with previous results. The results for acid mine drainage (AMD) water are worth noting. The recovery of the control polymer in AMD collapsed due to high concentrations of interfering sample matrix, especially sulphate ions. This is not surprising since in IIP selectivity is based on size and shape in addition to ionic interaction.

The selectivity was also compared, by direct injection of the real-world sample (AMD) for both spiked and non-spiked samples into that obtained after IIP selective extraction. Despite a very low detection limit of the method for direct injection (below $1 \mu \mathrm{g} \cdot \ell^{-1}$ ) no $\mathrm{Cr}(\mathrm{VI})$ was obtained in the spiked sample. After IIP extraction, spiked Cr (VI) was detected in the sample (Table 4).

\section{Conclusion}

A selective IIP for extraction of $\mathrm{Cr}$ (VI) was prepared and optimised. The prepared IIP showed superior selectivity towards $\mathrm{Cr}$ (VI) in acid mine drainage water, where the selectivity of the control collapsed due to high amounts of sulphate ions. The MIP backbone provides an opportunity to prepare $\mathrm{Cr}$ (VI) adsorbent materials with high stability and durability under different conditions (acidic, basic and common organic solvents). Maximum binding capacity of $38 \mathrm{mg} \cdot \mathrm{g}^{-1}$ polymer was obtained from an initial concentration of $50 \mathrm{mg} \cdot \ell^{-1}$, which 
was slightly higher than the amount obtained by Neagu and Mikhalovsky (2010), $33 \mathrm{mg} \cdot \mathrm{g}^{-1}$, from an initial concentration of $138 \mathrm{mg} \cdot \ell^{-1}$, and also comparable to the $50 \mathrm{mg} \cdot \mathrm{g}^{-1}$ binding capacity obtained by Fang et al. (2007) from an initial concentration of $98 \mathrm{mg} \cdot \mathrm{m} \ell^{-1}$.

\section{Acknowledgements}

This work was supported by the National Research Foundation of South Africa and the Swedish Foundation for International Cooperation in Research and Higher Education (STINT, YR2009-7015).

\section{References}

ACAR FN and MALKOC E (2004) The removal of chromium(VI) from aqueous solutions by Fagus orientalis L. Bioresour. Technol. 94 13-15.

ANIRUDHAN TS, DIVYA L and SUCHITHRA PS (2009) Kinetic and equilibrium characterization of uranium(VI) adsorption onto carboxylate-functionalized poly(hydroxyethylmethacrylate)grafted lignocellulosics. J. Environ. Manage. 90 549-560.

BENHAMMOU A, YAACOUBI A, NIBOU L and TANOUTI B (2007) Chromium(VI) adsorption from aqueous solution onto Moroccan Al-pillared and cationic surfactant stevensite. J. Hazard. Mater. 140 104-109.

BIRLIK E, ERSÖZ A, AÇIKKALP E, DENIZLI A and SAY R (2007) $\mathrm{Cr}(\mathrm{III})$-imprinted polymeric beads: Sorption and preconcentration studies. J. Hazard. Mater. B140 110-116.

BROWER JB, RYAN RL and PAZIRANDEH M (1997) Comparison of ion-exchange resins and biosorbents for the removal of heavy metals from plating factory wastewater. Environ. Sci. Technol. 31 (10) 2910-2914.

CANDAN N, TÜZMEN N, ANDAC M, ANDAC CA, SAY R and DENIZLI A (2009) Cadmium removal out of human plasma using ion-imprinted beads in a magnetic column. Mater. Sci. Eng. C 29 144-152.

CANNON FS, PARETTE RB, NA C, CHEN W and HAGERUP B (2005) A method for perchlorate removal from ground water. US Patent 6881348.

CHAKRABORTY S and KUMAR PA (2009) Fixed-bed column study for hexavalent chromium removal and recovery by shortchain polyaniline synthesized on jute fiber. J. Hazard. Mater. 162 1086-1098.

DENG S and BAI R (2004) Removal of trivalent and hexavalent chromium with aminated polyacrylonitrile fibers: performance and mechanisms. Water Res. 38 2423-2431.

FANG J, GU Z, GANG D, LIU C, IITON ES and DENG B (2007) $\mathrm{Cr}(\mathrm{VI})$ removal from aqueous solution by activated carbon coated with quaternised poly(4-vinylpyridine). Environ. Sci. Technol. 41 4748-4753.

GANG D, BANERJI SK and CLEVENGER TE (2000) Chromium(VI) removal by modified PVP-coated silica gel. Pract. Period. Hazard. Toxic Radioact. Waste Manage. 4 (3) 105-110.

GOUDARZIAN N, GHAHRAMANI P and HOSSINI S (1996) Polymeric reagent (I): Polyethyleneimine-supported silver dichromate as a new oxidizing agent. Polym. Int. 39 61-62.

GOYAL N, JAIN SC and BANERJEE UC (2003) Comparative studies on the microbial adsorption of heavy metals. Adv. Environ. Res. 7 $311-319$.

HUANG CP and WU MH (1977) The removal of chromium(VI) from dilute aqueous solution by activated carbon. Water Res. 11 (8) 673-679.
KATZ SA and SALEM H (1994) The Biological and Environmental Chemistry of Chromium. VCH, New York.

KRATOCHVIL D, PIMENTEL P and VOLESKY B (1998) Removal of trivalent and hexavalent chromium by seaweed biosorbent. Environ. Sci. Technol. 32 (18) 2693-2698.

LEE MY, HONG KJ, SHIN-Y AY and KAJIUCHI T (2005) Adsorption of hexavalent chromium by chitosan-based polymeric surfactants. J. Appl. Polym. Sci. 96 47-50.

LI Y, YANG MJ and SHE Y (2005) Humidity sensitive properties of crosslinked and quaternized poly(4-vinylpyridine-co-butyl methacrylate). Sensor Actuat. B 107 252-257.

LI $Z$ and BOWMAN RS (2001) Retention of inorganic oxyanions by organo-kaolinite. Water Res. 35 3771-3776.

NEAGU V, UNTEA I, TUDERACHE E and ORBECI C (2004) Sorption equilibrium of $\mathrm{Cr}(\mathrm{VI})$ ions by strong base anion exchangers with pyridine structures. J. Appl. Polym. Sci. 93 1957-1963.

NEAGU V (2009) Removal of Cr(VI) onto functionalised pyridine copolymer with amide groups. J. Hazard. Mater. 171 410-416.

NEAGU V and MIKHALOVSKY S (2010) Removal of hexavalent chromium by new quaternized crosslinked poly(4-vinylpyridines). J. Hazard. Mater. 183 533-540.

McBRIDE MB (1997) A critique of diffuse double layer models applied to colloid and surface chemistry. Clays Clay Miner. 45 (4) 598-608.

MILLER FA and WILKINS CH (1952) Infrared spectra and characteristic frequencies of inorganic ions. Anal. Chem. 24 1253-1294.

MITCHELL MD, COLLIAS DI, BJORKQUIST DW, ZAVERI PN and WOOLLEY MM (2004) Water filter materials, water filters and kits containing particles coated with cationic polymer and processes for using the same. U.S. Pat. Appl. Publ. (2004164018) Cont.-in-part of U.S. Ser. No. 464, 210. 30 pp.

PATTERSON JW (1985) Industrial Wastewater Treatment Technology ( $2^{\text {nd }}$ edn.) Butterworth-Heinemann, London.

QIAN S, HUANG C, JIANG J, HE F and WANG Y (2000) Studies of adsorption behaviour of crosslinked chitosan for $\mathrm{Cr}(\mathrm{VI})$ and Se(VI). J. Appl. Polym. Sci. 77 3216-3219.

RAJI C and ANIRUDHAN TS (1998) Batch Cr(VI) removal by polyacrylamide-grafted sawdust: Kinetics and thermodynamics. Water Res. 32 3772-3780

RAMNANI SP and SABHARWAL S (2006) Adsorption behaviour of $\mathrm{Cr}(\mathrm{VI})$ onto radiation crosslinked chitosan and its possible application for the treatment of wastewater containing $\mathrm{Cr}(\mathrm{VI})$. React. Funct. Polym. 66 902-909.

RAMOS J, MILLÁNA and PALACIO F (2000) Production of magnetic nanoparticles in a polyvinylpyridine matrix. Polymer $\mathbf{4 1}$ 8461-8464.

SANTIAGO I, WORLAND VP, CAZARES-RIVERA E and CADENA F (1992) Removal of hexavalent chromium from water using tailored zeolites. Met. Finish. 90 (11) 37-43.

SARIN V and PANT MM (2006) Removal of chromium from industrial waste by using eucalyptus bark. Bioresour. Technol. 97 (1) $15-20$.

SRINIVASAN K, BALASUBRAMANIAN N and RAMAKRISHAN TV (1988) Studies on chromium removal by rise husk carbon. Ind. J. Environ. Health 30 (40) 376-387.

TUNÇELI A and TÜRKER AR (2002) Speciation of Cr(III) and $\mathrm{Cr}(\mathrm{VI})$ in water after preconcentration of its 1,5-diphenylcarbazone complex on amberlite XAD-16 resin and determination by FAAS. Talanta 57 1199-1204.

UNNITHAN MR and ANIRUDHAN TS (2001) The kinetics and thermodynamics of sorption of chromium (VI) onto the iron (III) complex of a carboxylated polyacrylamide-grafted sawdust. Ind. Eng. Chem. Res. 40 (12) 2693-2701.

VINCENT T and GUIBALF E (2001) Cr(VI) extraction using Aliquat 336 in a hollow fiber module made of chitosan. Ind. Eng. Chem. Res. 40 1406-1411. 
http://dx.doi.org/10.4314/wsa.v37i4.11 Available on website http://www.wrc.org.za

ISSN 0378-4738 (Print) $=$ Water SA Vol. 37 No. 4 October 2011 ISSN 1816-7950 (On-line) = Water SA Vol. 37 No. 4 October 2011 